\title{
Total follicular populations in ewes of high and low ovulation rates
}

\author{
L. P. Cahill, J. C. Mariana and P. Mauléon \\ I.N.R.A.-Station de Physiologie de la Reproduction, 37380 Nouzilly, France
}

\begin{abstract}
Summary. The total ovarian follicular populations were studied in two breeds of ewes which differed greatly in their ovulation rates. Thus 8 Romanov (mean ovulation rate $3 \cdot 1)$ and 12 Ile-de-France ewes (mean ovulation rate 1.4) were ovariectomized at oestrus during the breeding season. Each right ovary and 3 left ovaries were sectioned at $7 \mu \mathrm{m}$ and examined microscopically. The number of small follicles, i.e. with 2 or less layers of granulosa cells, was estimated by a tested sampling procedure whilst all larger follicles were measured and arranged into classes. There were half as many small follicles but 1.5-2 times more large follicles in the ovaries of the Romanov ewes compared to those of the Ile-de-France ewes. The number of atretic follicles was approximately the same in both breeds and does not explain the difference observed in ovulation rate.

It is concluded that the higher ovulation rate in the Romanov ewe is due to the greater number of large follicles available to be stimulated for ovulation.
\end{abstract}

\section{Introduction}

Total ovarian follicular populations and their relationship with ovulation rate in adult ewes have not been defined. Land (1970) found that the number of small follicles in the ovary at birth of lambs of different breeds was inversely related to the subsequent ovulation rate of the breed and Trounson, Chamley, Kennedy \& Tassell (1974) also found a similar relationship within a breed which had been selected for and against multiple births. A similar situation has also been found in various strains of rats with different ovulation rates (Land, de Reviers, Thompson \& Mauléon, 1974). The correlation between the number of larger or growing follicles in the ovary of the ewe and their ovulation rate is unknown. In the ewe lamb at birth Land (1970) found more antral follicles present in those breeds of ewes which had higher ovulation rates but no difference in the total number of follicles with more than one layer of granulosa cells.

Several studies have attempted to correlate levels of circulating gonadotrophins in the adult ewe with the observed ovulation rate, but the only characteristic of the preovulatory LH discharge that can be correlated with ovulation rate is the interval between the onset of oestrus and the start of the discharge of LH (Thimonier \& Pelletier, 1971; Land, Pelletier, Thimonier \& Mauléon, 1973; Bindon, Blanc, Pelletier, Terqui \& Thimonier, 1976). Furthermore, attempts to correlate the level of peripheral FSH in the adult ewe with ovulation rate have so far been unsuccessful (Bindon et al., 1976). Much research has been devoted to manipulating ovulation rate by using exogenous gonadotrophins, particularly with PMSG which has follicle-stimulating ability (Cole \& Hart, 1930), but the results have tended to be variable and certainly unpredictable.

Therefore the physiological mechanism(s) which determine ovulation rate in the sheep remain unknown and the aim of this study was to establish the total ovarian follicular populations, during the breeding season, in adult ewes of two breeds of sheep which differ widely in their ovulation rate. 


\section{Materials and Methods}

\section{Definitions}

The total follicular population was divided into 2 parts according to the number of layers of granulosa cells with the start of the third layer of cells as the arbitrary dividing line.

Small follicles were those which were actively growing or not growing but had 2 or less layers of granulosa cells. The number of such follicles was estimated by counting the follicles in a sample of sections from each ovary.

Large follicles were those with 3 or more layers of granulosa cells and included both preantral and antral follicles. In this study all such follicles were counted and their surface area was measured.

Preovulatory follicles. All ovaries were fixed between the onset of oestrus and ovulation because Smeaton \& Robertson (1971) have shown the largest follicles seen at this time are those which eventually ovulate. A follicle was considered as preovulatory if (1) there was no sign of atresia (see below), (2) it was at least $3 \mathrm{~mm}$ in diameter and thus at least twice as large as the next largest follicles (in general the preovulatory follicles were 4 or 5 times larger than the next largest follicles), and (3) the cells around the oocyte were dispersed although this cell formation was not always present and depended on when the ovaries were fixed.

Atresia. The only criterion used for atresia was the presence of 4 or more pyknotic bodies along the edge of or among the granulosa cells of the follicle on that section where the nucleolus was found. Follicles in which atresia was very advanced, i.e. late atresia, with a large number of pyknotic bodies, widespread disintegration of the granulosa cells and absence of the oocyte, were not considered or counted.

\section{Procedure}

During November 1975 , oestrus was synchronized with progestagen-impregnated sponges in 8 Romanov and 12 Ile-de-France ewes. All ewes were primiparous, approximately 14 months of age, in good condition, housed together and had not been previously treated with PMSG.

From Day 15 after the second oestrus following synchronization a ram was placed with the ewes every $2 \mathrm{~h}$ for $15 \mathrm{~min}$ to detect oestrus, after which a blood sample of $10 \mathrm{ml}$ was taken by puncture of the jugular vein. The blood sample was immediately centrifuged and an aliquot of the plasma was assayed immediately for the $\mathrm{LH}$ concentration and the rest was stored at $-15^{\circ} \mathrm{C}$. When a ewe was observed in oestrus, it was allotted at random to one of 2 groups: in Group A the ewes were ovariectomized 2-4 h after the onset of oestrus ( 3 Romanov and 5 Ilede-France ewes) while in Group B the ewes were ovariectomized $10 \cdot 5-16.5 \mathrm{~h}$ after the start of the preovulatory discharge of $\mathrm{LH}$.

LH assay. The concentration of $\mathrm{LH}$ in the initial samples was determined by using a modified assay of that described by Pelletier, Kann, Dolais \& Rosselin (1968) in which the incubation times were reduced to $2 \mathrm{~h}$ for each antibody. The results of this rapid assay technique were later verified in the same plasma samples using the complete assay technique described.

\section{Determination of follicular populations}

After ovariectomy, both ovaries were fixed in Bouin-Hollande's solution. The ovaries that were to be examined were serially sectioned at a thickness of $7 \mu \mathrm{m}$ and all sections were mounted and stained with Feulgen's stain. The nucleolus of the oocyte was used as the marker for each follicle to avoid counting follicles twice.

Estimation of the population of small follicles. To find the within-ovary variation involved when using various sampling ratios all small follicles in all sections of 3 half ovaries ( 1 Romanov 
and 2 Ile-de-France) chosen at random were counted. The mean number of small follicles per section and the variance were determined (Text-fig. 1). Assuming that the variance in one half of an ovary was the same as that throughout the whole ovary, confidence limits at the level of $P=$ 0.05 were calculated for the entire ovary for sampling ratios ranging from $1 / 2$ to $1 / 120$. The confidence limits, as expected, widened in all cases as the sampling ratio increased and the extent to which these limits widened depended upon the variance, the number of follicles and the number of sections. With a sampling ratio of $1 / 120$ the confidence limits $(P=0.05)$ were \pm 3212 , \pm 6241 and \pm 7296 follicles for half ovaries with 6327,25323 and 39223 follicles and 570,690 and 708 sections respectively. No correction factors were used because the number of small follicles counted twice was considered to be small (maximum 14\%) in view of the thickness of the sections and the diameter of the nucleolus.

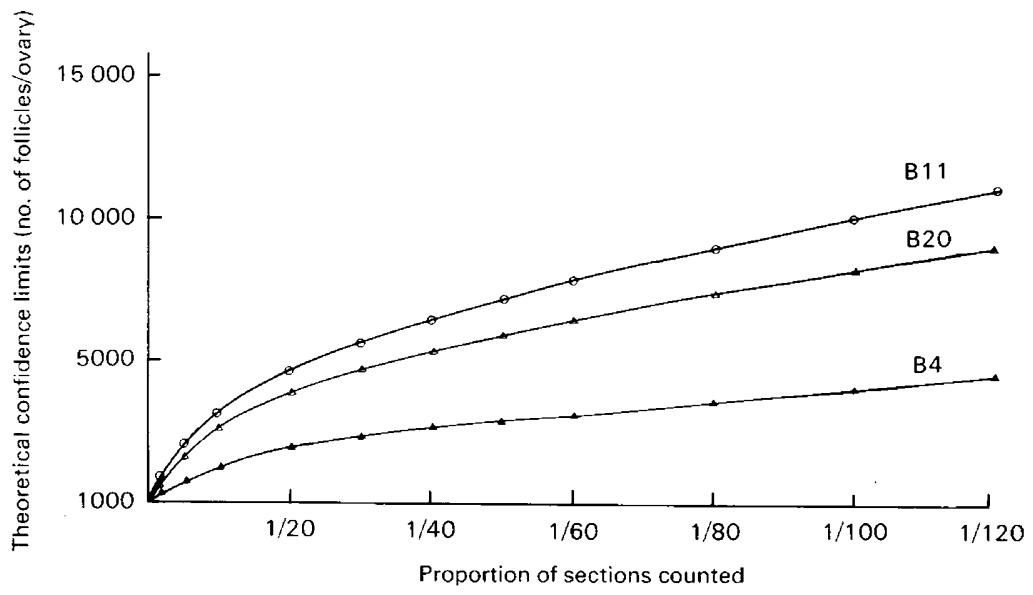

Text-fig. 1. Confidence limits $(P=0.05)$ in the estimation of the total number of small follicles in 3 different ovaries by counting the number of follicles in various numbers of sections. $\mathrm{B} 4=$ right ovary of a Romanov ewe, having $1140 \times 7 \mu \mathrm{m}$ thick sections and 12654 small follicles. B11 = right ovary of an Ile-de-France ewe, having $1416 \times 7 \mu \mathrm{m}$ thick sections and 78446 small follicles. B20 = right ovary of an Ile-de-France ewe, having $1380 \times 7 \mu \mathrm{m}$ thick sections and 50646 small follicles.

In all the other 17 ovaries 1 in every 120 sections was counted to compare the variation between ovaries to that within ovaries when using different sampling ratios. In all ovaries the total number of small follicles was estimated from the mean number of follicles per section observed and the number of sections per ovary.

Determination of the large follicle population. The right ovaries from 8 Romanov and 12 Ilede-France ewes and the left ovaries from 1 Romanov and 2 Ile-de-France ewes were used. Every section of each ovary was inspected under the light microscope and all large follicles were counted and the area of each follicle was measured on the section where the nucleolus was found. Whereas it is probably true that the oocyte and therefore nucleolus is more likely to be eccentric in the very large follicles the same method was used for both breeds and from consideration of the number of follicles counted this error was not likely to favour one or other of the breeds.

The area of the follicle was measured by using a graticule situated in the ocular lens of the microscope. This graticule consists of 4 series of lines drawn as hyperbolas and each series situated at $90^{\circ}$ to the adjoining series. The follicle was manipulated in the field of the microscope until its extremities tangentially touched the edge of the graticule in four places. The precise area within the graticule for each magnification was later calculated after measuring the two diameters intersecting at right angles. However, if the follicles were very large or irregular in shape they were measured with an over-head projection microscope and planimeter. The area of 
the antrum of a sample of follicles chosen at random for each breed was also measured with the over-head microscope and planimeter. The area of the antrum was only measured when its extremities could be easily distinguished and occupied about $20-90 \%$ of the area of the follicle. Extrapolation of the regression between the proportion of the area of the follicle occupied by the antrum and follicular size enabled a very precise definition of the follicular size when the antrum formation commenced.

The areas of all growing follicles were expressed in $\mu \mathrm{m}^{2}$ and transformed into logarithms because the follicular population curves are considered to be exponential (J. C. Mariana \& K.P. Read, personal communication). The data were then arranged into classes to facilitate handling. In the text, in order to conform with the normal convention of expressing follicular size by a mean diameter, the area of the follicle was then assumed to be circular and the diameter was calculated and expressed in $\mathrm{mm}$. The follicular classes used and expressed according to follicle diameter $(\mathrm{mm})$ are: $\leqslant 0.049,0.050-0.079,0.080-0.099,0 \cdot 100-0 \cdot 125,0.126-0.159,0 \cdot 160$ $0.199,0.200-0.251,0.252-0.319,0.320-0.399,0.400-0.503,0.504-0.633,0.634-0.799$, $0.800-1.005,1.006-1.268$ and $\geqslant 1.269$.

\section{Results}

The ovulation rate, calculated from the number of preovulatory follicles visible or, if not readily visible, the number of corpora lutea of the previous cycle, was 3.1 and 1.4 for the Romanov and Ile-de-France ewes respectively, values which accurately represent the normal ovulation rates for young ewes at this time of the breeding season (J. Thimonier, personal communication).

\section{Small follicles}

There was a highly significant difference $(P<0.01)$ between breeds in the mean number of small follicles, which was inversely related to the ovulation rate being $30501 \pm 5707$ (s.e.m.) in the Romanov ewes and $56236 \pm 5776$ in the Ile-de-France ewes. However, the variation between individuals was very large with values ranging from 11974 to 58191 and 20215 to

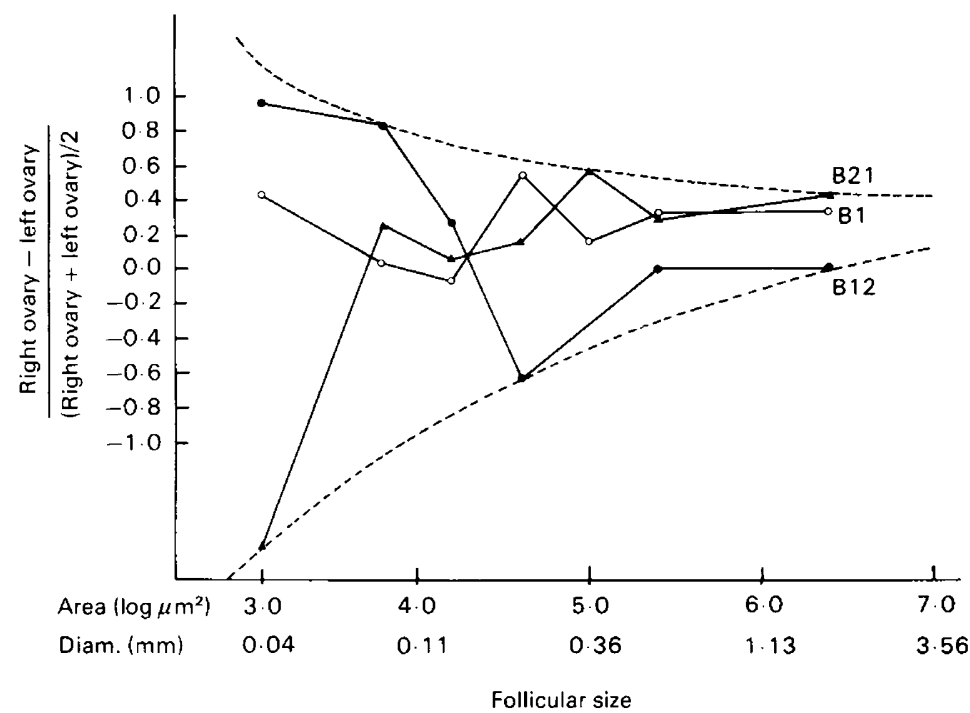

Text-fig. 2. Comparison of the populations of large follicles in the right and left ovaries of two Ile-de-France (Ewes B12, , and B21, $\Delta$ ) and one Romanov ewe (Ewe B1, O). 
86020 for the Romanov and Ile-de-France ewes respectively. The variance in the number of small follicles between ovaries of different animals was far greater than that incurred within one ovary with the sampling ratio used. For the Romanov ovary the within-ovary variance per section was 41.9 and the between-ovary variance per section was 103.6 ; similarly for the Ile-deFrance ewes the within-ovary variances/section for the 2 ovaries were 128.9 and 197.4 whereas the between-ovary variance per section was $242 \cdot 5$.

\section{Large follicles}

Right versus left ovary. Three right and left ovaries from the same animals (1 Romanov and 2 Ile-de-France) were compared and contained 227, 172 and 111 follicles and 193, 113 and 200 follicles respectively. The comparison per class between the right and left ovary showed that the largest difference occurred for the smallest follicles in the growing phase (Text-fig. 2) and that the relative difference per class decreased as the size of the follicles increased.

Breed differences. There was a significant difference $(P<0.05)$ in the number of large follicles per right ovary between breeds with the 8 Romanov ewes having $233 \pm 24 \cdot 1$ (s.e.m.) follicles and the 12 Ile-de-France ewes $150 \pm 20 \cdot 1$ large follicles. In contrast to the small follicles the number of large follicles was in the same order as the ovulation rate. Similarly, the variation between ewes in the number of follicles was large with ranges of 117-356 and 90-308 for the Romanov and Ile-de-France ewes, respectively. The frequency of large follicles for each size class is shown in Text-fig. 3. Except for the smallest class size there were $1.5-2.0$ times more large follicles in nearly all classes throughout the entire growth phase for the Romanov than for the Ile-de-France ewes. For both breeds there were 2 peaks of growing follicles at diameters of 0.09 and $0.25 \mathrm{~mm}$ but they differed in magnitude and between the peaks there was a large trough.

The mean numbers of normal and preovulatory follicles greater than $1.1 \mathrm{~mm}$ in diameter in

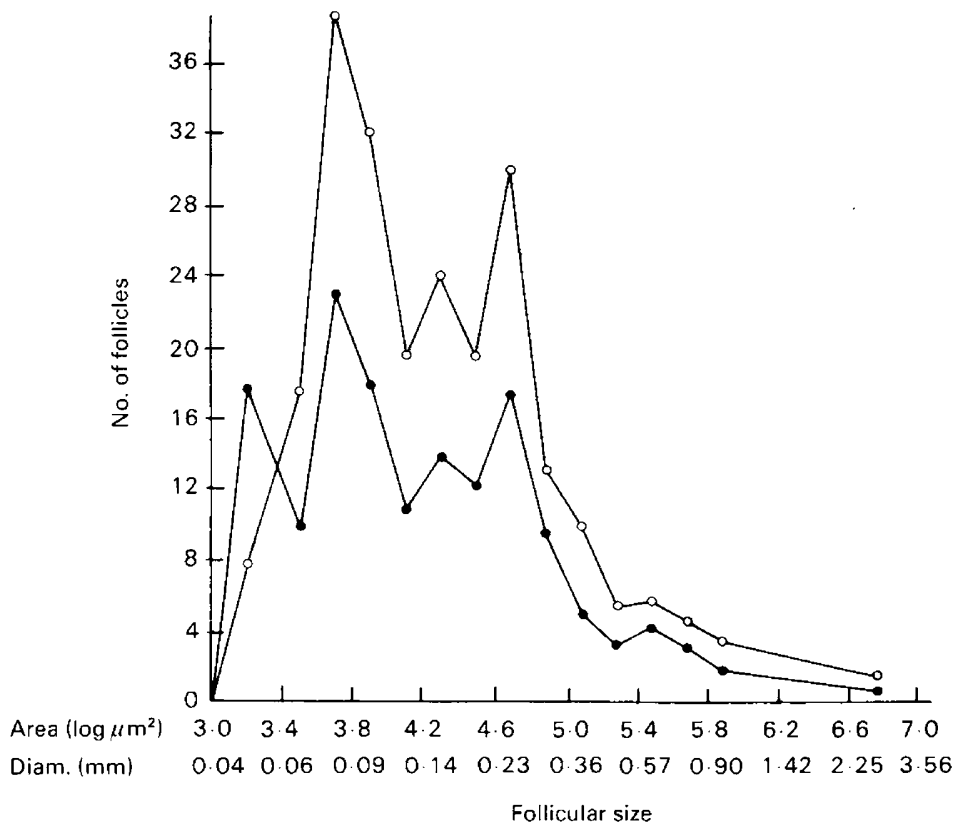

Text-fig. 3. The mean numbers per ovary of large follicles (i.e. more than 2 layers of granulosa cells) in various classes of follicular size in right ovaries from 8 Romanov ewes $(O)$ and right ovaries from 12 Ile-de-France ewes (†). 
the right ovary were 5.8 and 1.4 respectively for the Romanov ewes and 4.0 and 0.4 respectively for the Ile-de-France ewes.

Within-breed differences and ovulation rate. Within the Ile-de-France breed the mean (s.e.m.) number of large follicles for the 5 twin-ovulating ewes was $175.0 \pm 40 \cdot 2$ and $132 \pm 20 \cdot 1$ for the 7 single-ovulating ewes. This difference is not significant. There were more large follicles for the twin ovulating ewes for nearly all classes of follicles (Text-fig. 4) but this difference was not as great as between the two breeds. The mean number of very large follicles greater than $1 \cdot 1$ $\mathrm{mm}$ in diameter was 4.6 normal plus 0.6 preovulatory follicles per ovary for the twin-ovulating ewes and 3.7 normal plus 0.3 preovulatory follicles for the single-ovulating ewes.

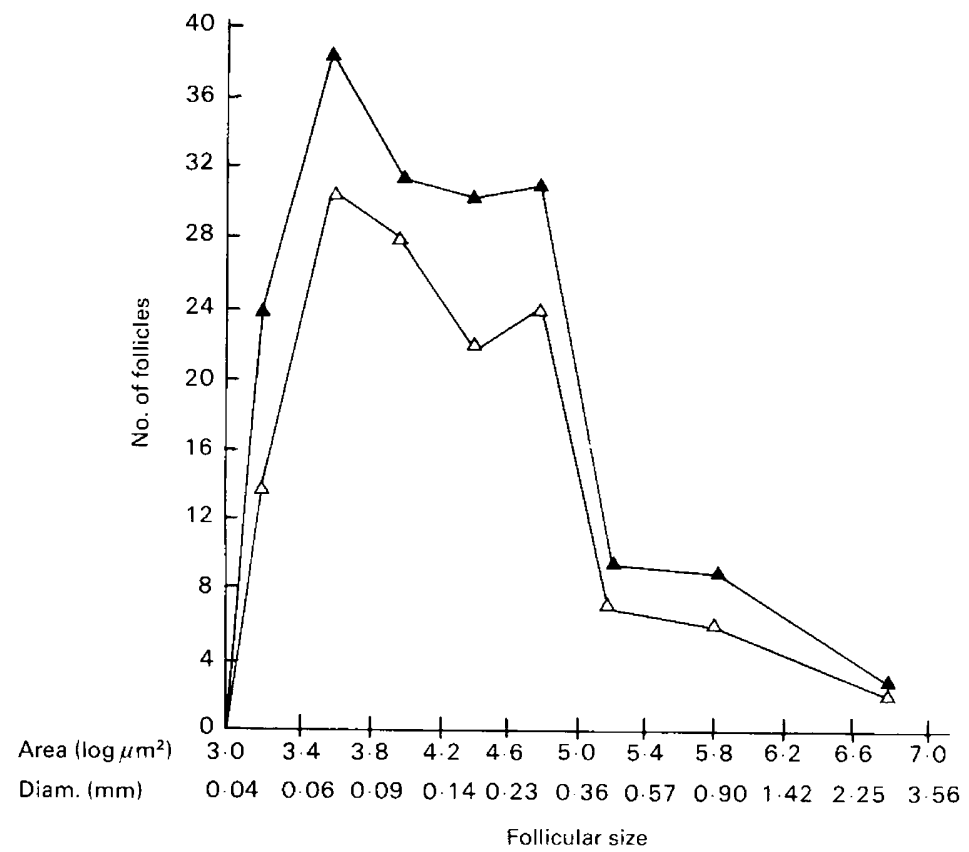

Text-fig. 4. The mean numbers per ovary (per 2 classes) of large follicles in various classes of follicular size in right ovaries of lle-de-France ewes with single $(\triangle, 7$ ewes) or twin $(\boldsymbol{\Delta}, 5$ ewes) ovulations.

Appearance of the antrum. The antral area was measured for the various classes of 93 and 68 follicles chosen at random from Romanov and Ile-de-France ovaries respectively. The linear regressions of the percentage of the follicular area occupied by the antrum $(y)$ and the area of the follicle expressed in logarithm $(x)$ were $y=39.6 x-173$ for the Romanov ewes and $y=45.7 x$ -213 for the Ile-de-France ewes.

The slopes of these regression lines were not significantly different. By extrapolation of these regressions it was found that the antrum began to appear at follicular diameters of 0.17 and 0.24 $\mathrm{mm}$ in the Romanov and Ile-de-France ewes respectively.

Correlation between classes of follicles. A correlogram was tested between classes of follicles for each breed to test in how many adjoining classes the number of follicles in a given class are significantly correlated (Text-fig. 5). Significant correlations were found between 5 consecutive classes for both the Romanov $(P<0.05)$ and Ile-de-France $(P<0.01)$ breeds, e.g. the number of follicles in class 2 was significantly correlated with the number of follicles in class 6 but not with the number of follicles in class 7 .

Correlation between numbers of large and small follicles. There was no significant correlation between the total numbers of small and large follicles per animal either within or between breeds. 


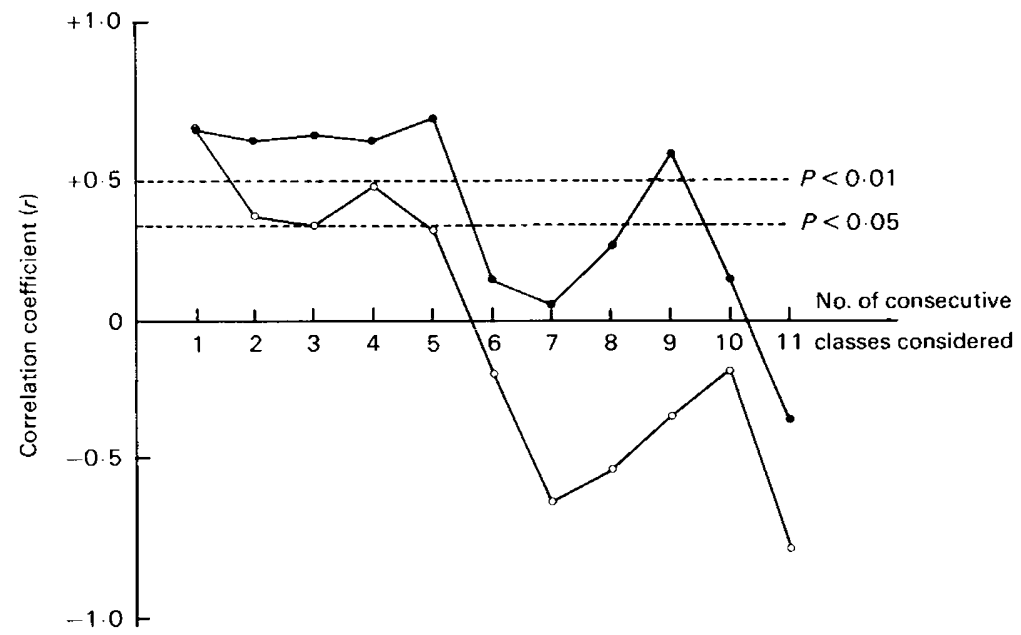

Text-fig. 5. The correlation coefficients of the number of follicles in consecutive classes for various numbers of consecutive classes considered (correlogram).

\section{Preovulatory follicles before and after the peak of $L H$}

The LH peaks occurred $18.4 \pm 2.4$ and $7.6 \pm 1.1 \mathrm{~h}$ after the onset of oestrus for the Romanov and Ile-de-France ewes respectively. There was no significant difference in the mean diameter of the largest follicle, defined as the preovulatory follicle, fixed before (i.e. $2-4 \mathrm{~h}$ after onset of oestrus) or after (i.e. 10.5-16.5 h after) the LH peak. Furthermore there was no significant difference between breeds in the size of the preovulatory follicle although those of the Romanov breed were slightly smaller $(3.89 \pm 0.27 \mathrm{~mm})$ than those of the Ile-de-France $(4.09 \pm$ $0.29 \mathrm{~mm}$ ).

\section{Atresia}

Using our limited definition of atresia the mean ( $t$ s.e.m.) numbers of atretic follicles per right ovary of the 8 Romanov and 12 Ile-de-France ewes examined were $10.0 \pm 1.6$ and $6.8 \pm$ 0.9 , respectively. There was no significant difference between breeds in the number of atretic follicles. Very few follicles which had not begun to form an antrum were found to be atretic. Only when follicles reached a diameter of $0.45 \mathrm{~mm}$ was there a large increase in the number and proportion of atretic follicles (Table 1). The number of atretic follicles was distributed throughout several classes per ewes and in general there were both atretic and normal follicles present in the same class.

Table 1. The mean number of atretic follicles per ovary and proportion* of atretic follicles in relation to follicular size in the right ovary from 8 Romanov and 12 Ile-de-France ewes

\begin{tabular}{|c|c|c|c|c|c|c|}
\hline \multirow[b]{2}{*}{ Breed } & \multicolumn{5}{|c|}{ Follicular size } & \multirow{2}{*}{$\begin{array}{c}\text { Total }( \pm \text { s.e.m. }) \\
\text { no. of atretic } \\
\text { follicles/ovary }\end{array}$} \\
\hline & $\begin{array}{l}\text { Area }\left(\log . \mu \mathrm{m}^{2}\right) \\
\text { Diam. }(\mathrm{mm})\end{array}$ & $\begin{array}{l}<5.0 \\
<0.36\end{array}$ & $\begin{array}{c}5 \cdot 0-5 \cdot 5 \\
0.36-0.67\end{array}$ & $\begin{array}{r}5 \cdot 5-6.0 \\
0.67-1 \cdot 1\end{array}$ & $\begin{array}{l}>6 \cdot 0 \\
>1 \cdot 1\end{array}$ & \\
\hline $\begin{array}{l}\text { Romanov } \\
\text { Ule-de-France }\end{array}$ & & $\begin{array}{l}0.2(0.1 \%) \\
0.1(0.1 \%)\end{array}$ & $\begin{array}{l}0.8(4 \%) \\
0.3(2 \%)\end{array}$ & $\begin{array}{l}2.6(32 \%) \\
0.9(22 \%)\end{array}$ & $\begin{array}{l}6.3(47 \%) \\
5.6(54 \%)\end{array}$ & $\begin{array}{r}10.0 \pm 1.56 \\
6.8+0.90\end{array}$ \\
\hline
\end{tabular}

* The proportion of atretic follicles is expressed as the number of atretic follicles per total number of follicles for a given follicular size range. 


\section{Discussion}

A schematic presentation of the total follicular populations in the right ovary of Romanov and Ile-de-France ewes (Text-fig. 6) clearly shows the important differences between the two breeds. The Romanov ewes which have the higher ovulation rate have fewer smaller follicles but more large follicles. The within-breed differences in the follicular populations of the single- and twinovulating Ile-de-France ewes show exactly the same profile although, probably due to the small number of animals, these differences were not significant. These results show that a very close association exists between ovulation rate and the population of growing follicles.

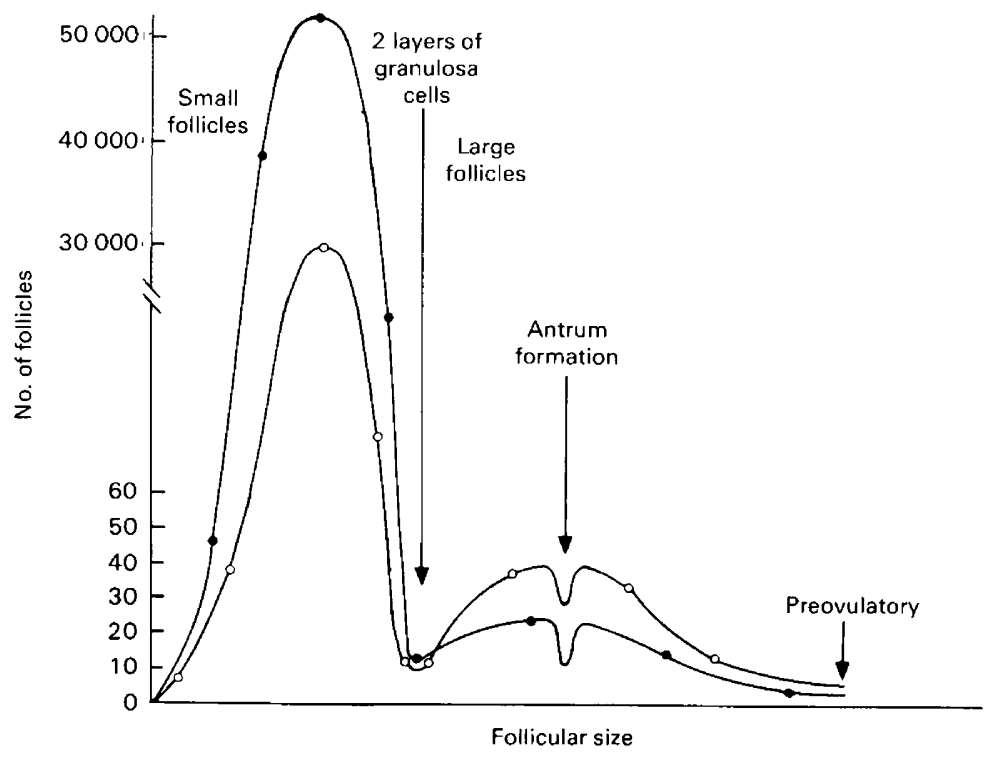

Text-fig. 6. Schematic diagram of the total follicular population in ewes with a high (e.g. Romanov) or low (e.g. Ile-de-France) ovulation rate.

As has been suggested by de Reviers \& Mauléon (1972), it is apparent that once follicles begin development any further development is under the control of the hypophysial hormones. The fact that in this present study there were more follicles throughout the entire growth phase, from 3 layers of granulosa cells onwards, in the ewes with a high ovulation rate strongly suggests that in these ewes the influence of $\mathrm{LH}$ and/or FSH on the follicular population is greater. This is further supported by the fact that the antrum developed at an earlier stage of follicular development in the Romanov than in the Ile-de-France ewes and FSH has long been known for its ability to cause antrum development, an ability originally used as a bioassay definition (Evans, Simpson, Tolksdorf \& Gensen, 1939). Furthermore Mariana \& Machado (1976) have shown in the rat that treatment with PMSG decreased the follicle size when antrum formation commenced. Bindon et al. (1976) and ourselves in this present experiment (unpublished data) have found that the overall level of circulating $\mathrm{FSH}$ throughout the oestrous cycle does not explain the difference observed in ovulation rate. Hence it must be assumed that this increased efficiency of FSH in ewes with a high ovulation rate must act at the ovarian level, possibly via the receptors.

Another approach is to consider the growing follicular populations of the ewes with either high or low ovulation rates to be a credit-debit situation. If we make the very dubious assumption that the follicular growth rate or the time for a follicle to grow through a given part of the growth curve is the same, despite the ovulation rate, then the rates at which follicles enter 
and leave the growth phase (which is principally by atresia) probably varies according to the ovulation rate. However, our results show that the rate at which follicles leave the growth phase does not vary according to the ovulation rate and therefore suggests that the rate follicles enter the growth phase from the reserve pool of primordial follicles and/or the rate follicles grow throughout the growth phase probably varies according to the ovulation rate. The relationship between the rate follicles enter the growth phase and grow throughout the growth phase and ovulation rate in the sheep remains unknown.

Although our definition of atresia was relatively limited and did not include all follicles that other authors have defined as atretic our results show that there was little difference in the number or proportion of atretic follicles between the two breeds. There was slightly more atresia in the very large follicles in the Ile-de-France ewes (54\%) than the Romanov ewes $(47 \%)$, but in determining the ovulation rate this difference is small compared to that of the difference in the number of normal follicles. Atresia was rarely found in follicles that had not begun to form an antrum, which agrees with the work of Turnbull, Braden \& Mattner (1977). Atretic follicles were found distributed throughout the last few classes of the follicular population with both atretic and normal follicles in the same class.

Our results can explain the findings of Bindon, Ch'ang \& Turner (1971) and Smith (1976) who reported that injection of high- and low-fecundity ewes with PMSG results in a greater response from the high-fecundity ewes. According to the results of Turnbull et al. (1977) the follicles which eventually ovulate are at approximately $1.0 \mathrm{~mm}$ in diameter on Day 12-13 when PMSG is normally injected and our results show that there are almost twice as many follicles of this size available to be stimulated in the high-fecundity ewes (i.e. in the Romanovs).

The correlogram of the large follicles shows that although a significant correlation existed between 5 classes for both breeds, there was no correlation between the number of follicles in any 2 classes that were more than 5 classes apart. The failure of the correlation after 5 classes is probably due to the disappearance of follicles by atresia, which upsets the correlation, and can explain why there were no significant correlations between the number of small and large follicles per animal.

Despite the small number of animals involved in the comparison of right and left ovaries, it is evident that follicles simultaneously exist in most classes in both ovaries. This suggests that some mechanism exists whereby one ovary can signal to the other ovary the state of its follicular development. However, it is evident that the classes of smaller follicles before antrum formation are less closely correlated between ovaries than are those of the larger follicles, indicating that some regulating mechanism is operating at the level of the very large follicles, a suggestion which agrees with the work of Land (1973) who found that the ovulation rate did not change after bilateral ovariectomy as late as Day 14 of the cycle. The presence of an inhibin-like substance which has a negative feed-back action on FSH has been shown in follicular fluid of the cow and sow (de Jong \& Sharp, 1976; Welschen, Hermans, Dullaart \& de Jong, 1977). Oestrogens, which have a negative feed-back action on $\mathrm{LH}$, are also present in large quantities in follicular fluid. It is attractive to suggest that this closer correlation between the very large follicles of each ovary is due to the feed-back action of substances from the follicular fluids acting on the gonadotrophins and follicular growth rates.

Examination of the preovulatory follicles before and after LH provided an opportunity to study the influence of the LH peak in determining the number of ovulations. It is highly probable that the follicles seen $2-4 \mathrm{~h}$ after the onset of oestrus do ovulate, although they did not all have the characteristic dispersed cells around the oocyte, because other follicles would probably not have enough time to develop to the preovulatory size. This would agree with the observations of Smeaton \& Robertson (1971) and Bherer, Matton \& Dufour (1977) which show that the large follicle observed at the surface of the ovary on Day 14-15 eventually ovulates. This strongly suggests that the follicles to ovulate have been selected and have already attained the preovulatory size at least at the time of the onset of oestrus and by which time steroidogenic 
changes have already occurred (Moor, Hay \& McIntosh, 1973). This preselection of the preovulatory follicle, probably some days before oestrus, explains the results of Thimonier \& Pelletier (1971) and Land et al. (1973) who found the ovulation rate to be independent of the maximum $\mathrm{LH}$ concentration reached and also demonstrates that the correlation between the interval onset of oestrus-onset of LH discharge and ovulation rate observed in these two studies is only a simple association with and not a cause of the difference in ovulation rate. Furthermore, it shows that the duration of the interval between the onset of oestrus and the start of the LH discharge, which has been correlated with the ovulation rate by the studies of Thimonier \& Pelletier (1971), Land et al. (1973) and Bindon et al. (1976), is only a simple association with, and not a cause of, the difference in ovulation rate as the preovulatory follicle has certainly already been selected and formed, probably some days before oestrus.

We thank Mrs Françoise Berthelot for her technical assistance throughout the experiment. L.P.C. was on study leave from Animal Research Institute, Werribee, Victoria, Australia.

\section{References}

Bherer, J., Matton, P. \& Dufour, J.J. (1977) Fate of the two largest follicles in the ewe after injection of gonadotrophins at two stages of the estrus cycle. Proc. Soc. exp. Biol. Med. 154, 412-414.

Bindon, B.M., Ch'Ang, T.S. \& Turner, H.N. (1971) Ovarian response to gonadotrophin by merino ewes selected for fecundity. Aust. J. agric. Res. 22, 809820.

Bindon, B.M., Blanc, M.R., Pelletier, J., Terqui, M. \& Thimonier, J. (1976) Oestrus et ovulation chez la brebis après induction de la luteolyse par un analogue des prostaglandines dans quatre troupeaux de prolificité différente. Annls Biol. anim. Biochim. Biophys. 16, 169, Abstr.

Cole, H.H. \& Hart, G.H. (1930) The potency of blood serum of mares in progressive stages of pregnancy in effecting sexual maturity of the immature rat. $A m . J$. Physiol. 93, 57-68.

de Jong, F.H. \& Sharpe, R.M. (1976) Evidence for inhibin-like activity in bovine follicular fluid. Nature, Lond. 263, 71-72.

de Reviers, M.M. \& Mauléon, P. (1972) Effect of hypophyseal gonadotrophins on ovarian follicular population in the immature rat. Annls Biol. anim. Biochim. Biophys., Suppl. 13, 177-192.

Evans, H.M., Simpson, M.E., Tolksdorf, S. \& Gensen, H. (1939) Biological studies of the gonadotrophic principles in sheep pituitary substance. Endocrinology 25, 529-546.

Land, R.B. (1970) Number of oocytes present at birth in the ovaries of pure and Finnish Landrace cross Blackface and Welsh sheep. J. Reprod. Fert. 21, $517-521$.

Land, R.B. (1973) The ovulation rate of Finn-Dorset sheep following unilateral ovariectomy and chloropromazine treatment at different stages of the oestrous cycle. J. Reprod. Fert. 33, 99-105.

Land, R.B., Pelletier, J., Thimonier, J. \& Mauléon, P. (1973) A quantitative study of genetic differences in the incidence of oestrus, ovulation and plasma luteinizing hormone concentration in the sheep. $J$. Endocr. 58, 305-317.
Land, R.B., de Reviers, M.M., Thompson, R. \& Mauléon, P. (1974) Quantitative physiological studies of genetic variation in the ovarian activity of the rat. J. Reprod. Fert. 38, 29-39.

Mariana, J.C. \& Machado, J. (1976) Etude de la formation de l'antrum dans les follicules de l'ovaire de Ratte et de Vache normales ou stimulées par PMSG. Annls Biol. anim. Biochim. Biophys. 16, 545-559.

Moor, R.M., Hay, M.F. \& MeIntosh, J.E.A. (1973) Effect of gonadotrophins on the production of steroids by sheep ovarian follicles cultured in vitro. $J$. Endocr. 58, 599-611.

Pelletier, J., Kann, G., Dolais, J. \& Rosselin, G. (1968) Dosage radioimmunologique de l'hormone luteinisante plasmatique chez le mouton. Mise au point technique de dosage. C. r. hebd. Séanc. Acad. Sci., Paris D 266, 2291-2294.

Smeaton, T.C. \& Robertson, M.C. (1971) Follicular development in the ovary of the sheep. $J$. Reprod. Fert. 25, 243-257.

Smith, J.F. (1976) Selection for fertility and response to PMSG in Romney ewes. Proc. N. Z. Soc. Anim. Prod. 36, 247-251.

Thimonier, J. \& Pelletier, J. (1971) Différence génétique dans la décharge ovulante (LH) chez les brebis de race Ile-de-France; relations avec le nombre d'ovulations. Annls Biol. anim. Biochim. Biophys. 11, 559-567.

Trounson, A.O., Chamley, W.A., Kennedy, T.P. \& Tassell, R. (1974) Primordial follicle numbers in ovaries and levels of $\mathrm{LH}$ and FSH in pituitaries and plasma of lambs selected for and against multiple births. Aust. J. biol. Sci. 27, 293-299.

Turnbull, K.E., Braden, A.W.H. \& Mattner, P.E. (1977) The pattern of follicular growth and atresia in the ovine ovary. Aust. J. biol. Sci. 30, 229-241.

Welschen, R., Hermans, W.P., Dullaart, J. \& de Jong, F.H. (1977) Effects of an inhibin-like factor present in bovine and porcine follicular fluid on gonadotrophin levels in ovariectomized rats. J. Reprod. Fert. 50, 129-131. 